\title{
Differentiation of mesenchymal stem cells in chitosan scaffolds with double micro and macroporosity
}

\author{
Dunia M. García Cruz, ${ }^{1,2}$ M. Gomes, ${ }^{3,4}$ Rui. L. Reis, ${ }^{3,4}$ David Moratal, $^{2}$ \\ Manuel Salmerón-Sánchez, ${ }^{1,2,5}$ Jose L. Gómez Ribelles, ${ }^{1,2,5}$ Joao F. Mano ${ }^{3,4}$ \\ ${ }^{1}$ Centro de Investigación Príncipe Felipe, Autopista del Saler 16, Valencia 46013, Spain \\ ${ }^{2}$ Centro de Biomateriales e Ingeniería Tisular, Universidad Politécnica de Valencia, Valencia 46022, Spain \\ ${ }^{3} 3 B^{\prime}$ 's Research Group (Biomaterials, Biodegradables and Biomimetics), Department of Polymer Engineering, University of \\ Minho, Braga 4710-057, Portugal \\ ${ }^{4}$ PT Government Associated Laboratory, IBB-Institute for Biotechnology and Bioengineering, Braga, Portugal \\ ${ }^{5}$ CIBER de Bioingeniería, Biomateriales y Nanomedicina (CIBER-BBN), Valencia, Spain
}

Received 7 January 2010; revised 22 April 2010; accepted 25 May 2010

Published online 5 October 2010 in Wiley Online Library (wileyonlinelibrary.com). DOI: 10.1002/jbm.a.32906

\begin{abstract}
Bone Marrow mesenchymal stem cells can be induced to differentiate into osteoblasts to regenerate damaged bone tissue using tissue engineering techniques. In this study, we examine the use of chitosan scaffolds with double pore structure prepared by an innovative method that combines freeze gelation (that produces micropores) and particle leaching out technique (that produces interconnected spherical macropores) seeking to enhance the osteogenic differentiation of goat bone marrow stromal cells (GBMSCs). The double pore architecture of the scaffold was characterized by scanning electron microscopy (SEM), microcomputed tomography and confocal laser scanning
\end{abstract}

microscopy. The obtained hierarchical pore structure allowed very efficient seeding of GBMSCs that are able to occupy the whole volume of the scaffold, showing good adhesion and proliferation. GBMSCs were differentiated into osteoblasts as indicated by alkaline phosphatase activity and osteocalcin expression. The results of this study demonstrate that chitosan scaffold may be promising biomaterial for bone regeneration. (c) 2010 Wiley Periodicals, Inc. J Biomed Mater Res Part A: 95A: 1182-1193, 2010.

Key Words: chitosan, macroporous scaffolds, mesenchymal stem cells, tissue engineering

\section{INTRODUCTION}

Current bone tissue engineering strategies are focused on the restoration of damaged tissue architecture by transplantation of cells in combination with a suitable three-dimensional scaffold. ${ }^{1}$ Mesenchymal stem cells (MSCs) presenting in bone marrow have a high ability to renew and differentiate themselves into various lineages of conjunctive cells including osteoblasts ${ }^{2,3}$ as bone progenitors cells., ${ }^{4,5}$ MSCs can be seeded into three-dimensional scaffolds and differentiated to form tissue-engineered construct ${ }^{6}$ under appropriate culture conditions.

A number of biodegradable materials including synthetic $^{7-9}$ and natural ${ }^{10-12}$ polymers have been exhaustively explored as supportive scaffolds for bone tissue engineering applications. Among them, naturally derived polymers are of special interest due to, as natural components of living structures, their biological and chemical similarities to natural tissues. ${ }^{13}$ Chitosan (CHT) is a biocompatible and biode- gradable polysaccharide; its degradation products, CHT oligosaccharides, are also biocompatible. In addition, CHT can be processed into interconnected porous structure by freeze-drying, freeze-gelation, and other techniques. ${ }^{14,15}$ The interconnected porous structure is a promising characteristic for cell colonization rate, nutrient perfusion, and functionality of the tissue-engineered construct. ${ }^{16-18}$ Porosity, pore interconnectivity, pore architecture, that is, pore shape, size, distribution, and orientation also affect the mechanical properties and degradation rate of the scaffolds. Madihally and Mattew ${ }^{15}$ studied the influence of porous structure on tensile testing of hydrated porous and nonporous membranes. The results obtained reveal that elastic moduli of porous membrane are 10-fold lower than those of nonporous membrane.

Enzymatic degradation of CHT porous materials depends greatly on CHT characteristics (molecular weight, deacetylation degree, etc.) but also on porosity and interconnected

Correspondence to: D. M. García Cruz; e-mail: dugarcru@ter.upv.es

Contract grant sponsor: Spanish Ministry of Education (including the FEDER financial support); contract grant number: MAT2007-66759-C03-01 Contract grant sponsor: Science and Innovation Ministry; contract grant number: PTA2008-0943-P

Contract grant sponsor: Generalitat Valenciana (Grups d'investigació Emergents); contract grant number: GV/2009/126

Contract grant sponsors: VI National R\&D\&i Plan 2008-2011, Iniciativa Ingenio 2010, Consolider Program, CIBER Actions, Instituto de Salud Carlos III (European Regional Development Fund)

Contract grant sponsor: FCT project; contract grant number: PTDC/QUI/68804/2006 
porous structure because the degradation medium diffusion is favored in highly porous materials. On the other hand, the biodegradation rate plays a crucial role on the longterm applications of cell/scaffold construct because it affects many cellular processes including cell growth and regeneration of tissue.

CHT-based materials have been used in bone tissue engineering as it was shown that they promote growth and mineral rich matrix deposition by osteoblasts in culture. ${ }^{19-24}$ However, CHT-based scaffolds have been usually processed using single techniques that induce structures exhibiting frequently pores with sizes of the same range and with limited interconnectivity. The combination of different processing methodologies could be a strategy to obtain more complex and interconnected structures. ${ }^{25-28}$

Many studies focused in a combination of CHT with other polymer or inorganic materials to enhance the mechanical properties and bioactivity. In this work, CHT scaffolds with a controlled porous structure, including micro and macropores, were designed by a new fabrication method based in the combination of both freeze-gelation and leaching out techniques. This methodology can be used to generate scaffolds with morphological and mechanical properties more selectively designed to meet the specificity of bone-repair needs. In this study, the morphology, microarchitecture of the interconnected porous structure of CHT scaffold was assessed and the biological response of the material was investigated by the osteogenic differentiation of MSCs isolated from goat bone marrow.

\section{EXPERIMENTAL PART}

\section{Materials}

CHT derived from crab shells was purchased from Sigma Aldrich (practical grade, Cat. No: 417963, Madrid, Spain) with deacetylation degree of $75 \%$ determined by first derivative UV spectrophotometry. ${ }^{29}$ Viscosity-average molecular weight of $1.5 \times 10^{6} \mathrm{~g} / \mathrm{mol}$ was determined by Mark-Houwink equation using $0.1 M \mathrm{CH}_{3} \mathrm{COOH} / 0.2 \mathrm{M} \mathrm{NaCl}$ as a solvent system at $25^{\circ} \mathrm{C}$. Poly(ethyl methacrylate) microspheres with molecular weight of $50 \times 10^{3} \mathrm{~g} / \mathrm{mol}$ and average microsphere diameter of $200 \mu \mathrm{m}$, used as porogen, were supplied by Lucite International (Tennessee, USA). Lysozyme from hen egg-white, sodium azide, and phosphate-buffered solution (PBS, pH 7.4) were supplied from Sigma-Aldrich. Sodium hydroxide $(\mathrm{NaOH})$, absolute ethanol, acetic acid (HPLC grade), and other reagents were obtained from Scharlau (Valencia, Spain) and used without further purification. For cell culture studies, $\alpha$-minimum essential medium ( $\alpha$-MEM), sodium $\beta$-glycerophosphate, ascorbic acid, and dexamethasone were purchased from Sigma Aldrich (Madrid, Spain), and foetal bovine serum (FBS), penicillin-streptomycinamphotericin and trypsin- EDTA solution were obtained from $\mathrm{GIBCO} \cap$.

\section{Preparation of CHT scaffolds}

CHT scaffolds were prepared by a combination of freeze gelation and leaching out technique of poly(ethyl methacrylate) microspheres, used as porogen. CHT solutions with concentration of 4 wt \% were prepared by dissolution of CHT flakes in $0.1 M$ acetic acid. CHT solutions were poured into a cylindrical mold, mixed with 70 wt \% of PEMA microspheres and frozen in liquid nitrogen $\left(-196^{\circ} \mathrm{C}\right)$. Then, they were soaked into a sodium hydroxide and ethanol mixture at $-20^{\circ} \mathrm{C}$ for 3 days. Afterward, the scaffolds were washed with distilled water until $\mathrm{pH} 7$ to remove the excess of $\mathrm{NaOH}$ and the porogen microspheres were removed by soxhlet extraction using absolute ethanol as a solvent during 3 days. Finally, the porous samples were transferred into freeze-drier (Telstar) and lyophilized at $-80^{\circ} \mathrm{C}$ for 3 days to ensure that they were completely dried. The size of scaffolds used for cell culture was $7 \mathrm{~mm}$ of diameter and $3 \mathrm{~mm}$ of thickness.

\section{Morphological analysis, architecture, and interconnectivity of CHT scaffolds}

Morphological analysis of CHT scaffolds were examined in a scanning electron Jeol JSM-5410, SEM, microscope. All specimens were coated with a conductive layer of sputtered gold. The micrographs were taken at an accelerating voltage of $20 \mathrm{kV}$ in order to ensure a suitable image resolution. The architecture and interconnectivity of porous materials were performed by microcomputed tomography ( $\mu$-CT) imaging using a SkyScan1072 system (Kontuch, Belgium) with penetrative X-rays of $50 \mathrm{keV}$. The X-ray scans were acquired in high-resolution mode. Mimicss software (Materialise, Belgium) was used to visualize the 2D X-ray sections images of the materials layered scaffolds. From the $\mu$-CT data set, 200 slice of a region of interest were used to investigate the continuity of the porous materials.

\section{Pore size characterization using image analysis}

An in-house software, called ESTRA, ${ }^{30}$ was developed using MATLAB R2007a (The Mathworks, Inc., Natick, MA) to characterize $3 \mathrm{D}$ structures through image analysis. The $\mu$-CT images were processed as a series of 200 slices of $1024 \times$ 1024 pixels with a spatial resolution of $7.13 \mu \mathrm{m}$. Before performing a structural and mechanical analysis to the $\mu$-CT images, a preprocessing consisting of segmentation and binarization steps was performed in order to reduce computational burden.

For segmentation, a squared region of interest (ROI) of 400 pixels edge was selected in each slice by an automated algorithm in order to process a representative sample of the scaffold. Resultant grayscale images were stored in a threedimensional matrix representing a 3D reconstruction of the specified volume of interest (VOI) of the scaffold, considering isotropic voxels.

Afterwards, images were converted to its binarized version in order to discriminate structure voxels from empty voxels. The optimum threshold value applied during binarization was calculated for each slice using Otsu's method. ${ }^{31}$ Binarized images were stored in a 3D binary matrix compounding a logical representation of the VOI.

Measurement of structure separation or mean pore size was assessed by a 3D algorithm. The method consisted of a structural voxel by voxel inspection. That is, in a given voxel 
corresponding to a pore (black voxel), number of contiguous voxels on $X$ direction are first counted, then the same is done for $\mathrm{Y}$, and finally for $\mathrm{Z}$. Then, if we average the contiguous voxels in the three directions, we obtain the mean local pore size. Repeating this process for all pore voxels, mean pore size as well as pore size distributions were obtained. These histograms have been gracefully used to assess the effectiveness of the scaffold manufacture process.

\section{In vitro degradation}

The in vitro degradation of CHT scaffolds was followed in $5 \mathrm{~mL}$ of PBS containing $10 \mu \mathrm{g} / \mathrm{mL}$ lysozyme and 0.02 wt $\%$ of sodium azide at $37^{\circ} \mathrm{C}$. The concentration of lysozyme was chosen to correspond to the concentration in human serum. $^{32-34}$ Briefly, CHT scaffolds of known dry weight were incubated in the lysozyme solution and placed into the water bath with orbital shaker (Unitronic OR, Selecta) at $50 \mathrm{rpm}$ for the period of study. The lysozyme solution was refreshed every 3 days to guarantee continuous enzyme activity. After 7, 14, 35, and 45 days, samples were removed from the medium, rinsed in distilled water, and dehydrated with solutions of increasing contents of ethanol up to constant weight. The extent of in vitro degradation was expressed as percentage of weight loss of the dried scaffolds after lysozyme treatment.

\section{Isolation and culture of goat bone marrow stromal cells (GBMSCs)}

Bone marrow stromal cells were isolated from the iliac crest of adult goats and cultured with Dulbecco's Modified Eagle's Medium (DMEM) supplemented with $10 \%$ fetal bovine serum, (FBS; Gibco, UK) and antibiotic/antimycotic (1\% A/B, Gibco, UK) solution containing 10,000 units/mL penicillin G sodium, $10,000 \mathrm{mg} / \mathrm{mL}$ streptomycin sulphate and $25 \mathrm{mg} / \mathrm{mL}$ amphotericin B as Fungizones ${ }^{\circledR}$ in 0.85 vol \% saline until confluence and subcultured at passage 1 or 2 before seeding.

\section{GBMSCs cultured into porous CHT scaffolds and cell differentiation}

CHT scaffolds prepared as described above were sterilized by ethylene oxide under conditions previously described ${ }^{35}$ and immersed in $\alpha$-MEM for $24 \mathrm{~h}$ prior to cell seeding.

GBMSCs cells were enzymatically lifted with $3 \mathrm{~mL}$ of trypsin after reaching $80 \%$ of confluence and a cell suspension at a cellular density of $1 \times 10^{5}$ cells/scaffolds was injected into the CHT scaffolds and then incubated at $37^{\circ} \mathrm{C}$ under $5 \%$ of $\mathrm{CO}_{2}$ conditions for $1 \mathrm{~h}$. After this time, $800 \mu \mathrm{L}$ of fresh medium was added to each well. For inducing osteogenic differentiation, cells/scaffolds constructs were cultured in 48-well plates for 3 days, 1, 2, 3, and 4 weeks with osteogenic differentiation media consisting of $\alpha$-MEM supplemented with osteogenic supplements namely, $10^{-8} M$ dexamethasone, $50 \mathrm{mg} / \mathrm{mL}$ ascorbic acid, and $10 \mathrm{mM} \beta$ glycerophosphate. Osteogenic medium was renewed every 3 days. Each experiment was conducted in triplicate. Porous materials without cells processed and cultured under the same conditions were used as reference.

\section{Cell viability assay}

The viability of GBMSCs cultured for 3 days, 1, 2, 3, and 4 weeks onto the CHT scaffolds was determined using MTS 3(4,5-dimethylthiazol-2-yl)-5-(3-carboxymethoxyphenyl)-2-(4sulfophenyl)-2H-tetrazolium) assay following manufacturer instructions (Promega). The assay is based on the mitochondrial activity of living cells. MTS tetrazolium compound is bioreducted by cells into a colored formazan product that is soluble in tissue culture medium. This conversion is presumably accomplished by NADPH or NADH produced by dehydrogenase enzymes in metabolically active cells. The quantity of formazan product is directly proportional to the number of living cells in culture. The samples were washed twice with PBS and incubated with fresh culture medium without phenol red and FBS containing MTS reagent (ratio $5: 1)$ at $37^{\circ} \mathrm{C}$ for $3 \mathrm{~h}$ in darkness. After the incubation period, the absorbance was quantified by photospectrometery at $490 \mathrm{~nm}$ with a microplate reader (Bio-TeK, USA). The correct absorbance was calculated subtracting the sample absorbance of the controls (without cells).

\section{Total DNA quantification}

The DNA content of GBMSCs cultured onto CHT scaffolds was assessed at each incubation time (3 days, 1, 2, 3, and 4 weeks) using a fluorimetric dsDNA quantification kit (PicoGreen, Molecular Probes). Samples were washed with PBS and transferred into eppendorf tubes containing $1 \mathrm{~mL}$ of sterile ultra-pure water and then stored in a $-80^{\circ} \mathrm{C}$ freezer until assayed to ensure complete cell lysis. Prior to DNA quantification, scaffold cell constructs were thawed at room temperature and sonicated for $15 \mathrm{~min}$. Standards were prepared as serial dilutions in ultra-pure water of a $100 \mu \mathrm{g} / \mathrm{mL}$ DNA stock solution. Aqueous working solution of the Quant-iT ${ }^{\mathrm{TM}}$ PicoGreen ${ }^{\circledR}$ reagent was prepared as a ratio $1 / 200$ in $1 \mathrm{X}$ TE buffer (10 $\mathrm{m} M$ Tris- $\mathrm{HCl}, 1 \mathrm{~m} M$ EDTA). $28.7 \mu \mathrm{L}$ of samples and standards plus $71.3 \mu \mathrm{L}$ of PicoGreen solution and $100 \mu \mathrm{L}$ of $1 \mathrm{X}$ TE buffer were added to individual wells of 96-well plate and incubated for 2 to $5 \mathrm{~min}$ at room temperature, protected from the light prior to measuring the fluorescence using a microplate reader.

Evaluation of GBMSCs adhesion and morphology by SEM Scaffold-cell constructs were washed twice with PBS and fixed with $2.5 \mathrm{v} / \mathrm{v}$ glutaraldehyde in PBS at $4^{\circ} \mathrm{C}$ for $1 \mathrm{~h}$. Dehydration process was performed by sequential immersion in serial diluted ethanol solutions $(50,60,70,80,90$,

TABLE I. Primary Antibodies Used for Immunofluorescence Assay

\begin{tabular}{ccc}
\hline \multicolumn{2}{c}{ Primary Antibody } & Supplier \\
\hline Antihuman collagen & Rabbit, & Chemicon, \\
type I & polyclonal & USA \\
Antihuman/mouse/rat & Mouse, & R\&D Systems, \\
alkaline phosphatase & monoclonal & USA \\
Antihuman osteocalcin & Mouse, & R\&D Systems, \\
& monoclonal & USA \\
\hline
\end{tabular}



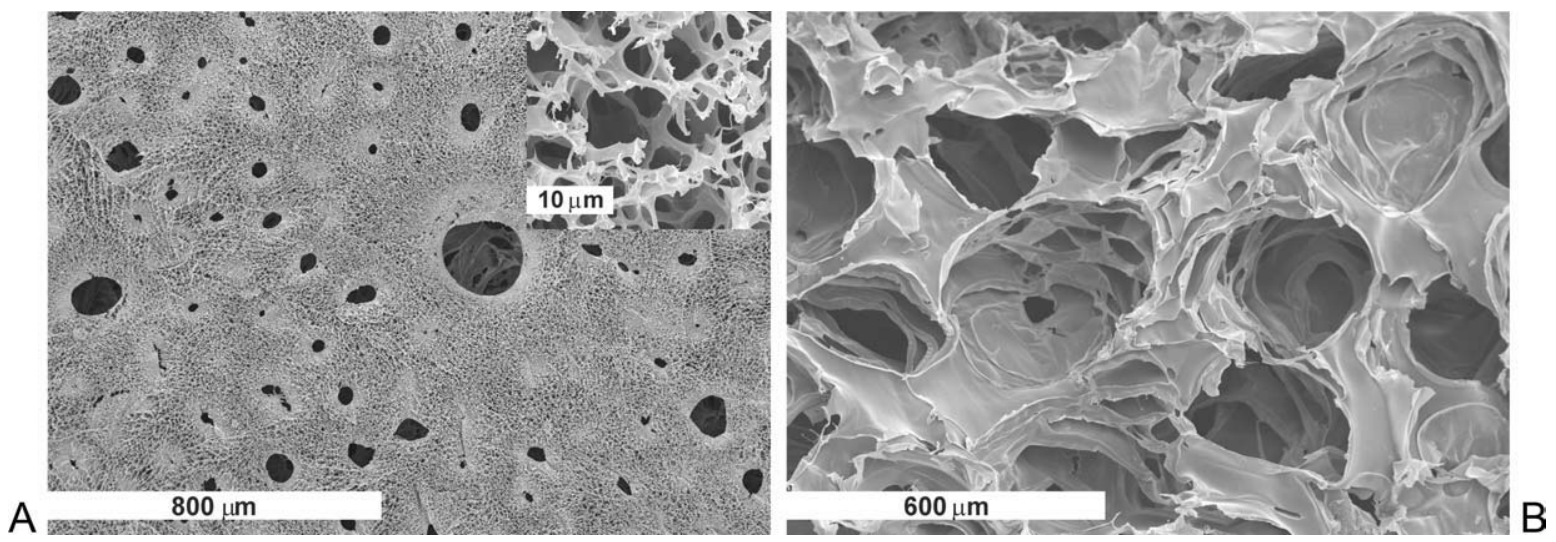

FIGURE 1. SEM microphotographs of surface (A) and cross-section view (B) of CHT scaffolds produced with 70 wt \% PEMA microspheres used as porogen. The inset in the surface image corresponds to a high magnification detail.

and $100 \% \mathrm{v} / \mathrm{v}$ ) after that, the samples were air-dried at room temperature overnight. Finally, scaffold-cell constructs were sputter-coated with gold using a Fisons Instrument Coater (Polaron SC 502, UK) with a current set at $18 \mathrm{~mA}$, for a coating time of $120 \mathrm{~s}$ and observed using a Leica Cambridge S-360, UK scanning microscope.

\section{Osteoblastic specific markers detection}

Alkaline phosphatase activity by colorimetric analysis. Alkaline phosphatase activity (ALP) was measured to evaluate the osteoblastic differentiation. Cell lysates were incubated in substrate solution (2 $\mathrm{m} M p$-nitrophenyl phosphate (pNp, Sigma), in a substrate buffer ( $1 M$ diethanolamine at $\mathrm{pH}$ 9.8) for $45 \mathrm{~min}$ in the dark at $37^{\circ} \mathrm{C}$. After the incubation time, the reaction was stopped by adding $2 M$ of sodium hydroxide and $0.2 \mathrm{~m} M$ EDTA and the product was quantified at $405 \mathrm{~nm}$ using a set of pNp standards.

\section{Von Kossa staining}

von Kossa staining is a standard procedure for the detection of mineralized tissue on different biomaterials. The cell-scaffold constructs were fixed in neutral buffered $10 \%$ formalin 3 weeks after osteogenic induction and $1 \mathrm{~mm}$ sections were cut and stained. Scaffold sections were immersed in silver nitrate solution (5 wt \%) under UV light for $1 \mathrm{~h}$. The silver cation binds to anions, such as phosphates or carbonates, and turns into black color. Digital images were taken using an optical microscope (Nikon Eclipse E600).

\section{Immunofluorescence analysis}

Type I collagen, alkaline phosphatase and osteocalcin (OC) markers of osteoblastic differentiation were assessed by immunofluorescence. To analyze the osteogenic differentiation of the cells inside the scaffolds, the constructs were sectioned in two slices $(\sim 1 \mathrm{~mm})$ and fixed with formalin, washed with PBS twice and permeabilized with 0.1 vol \%
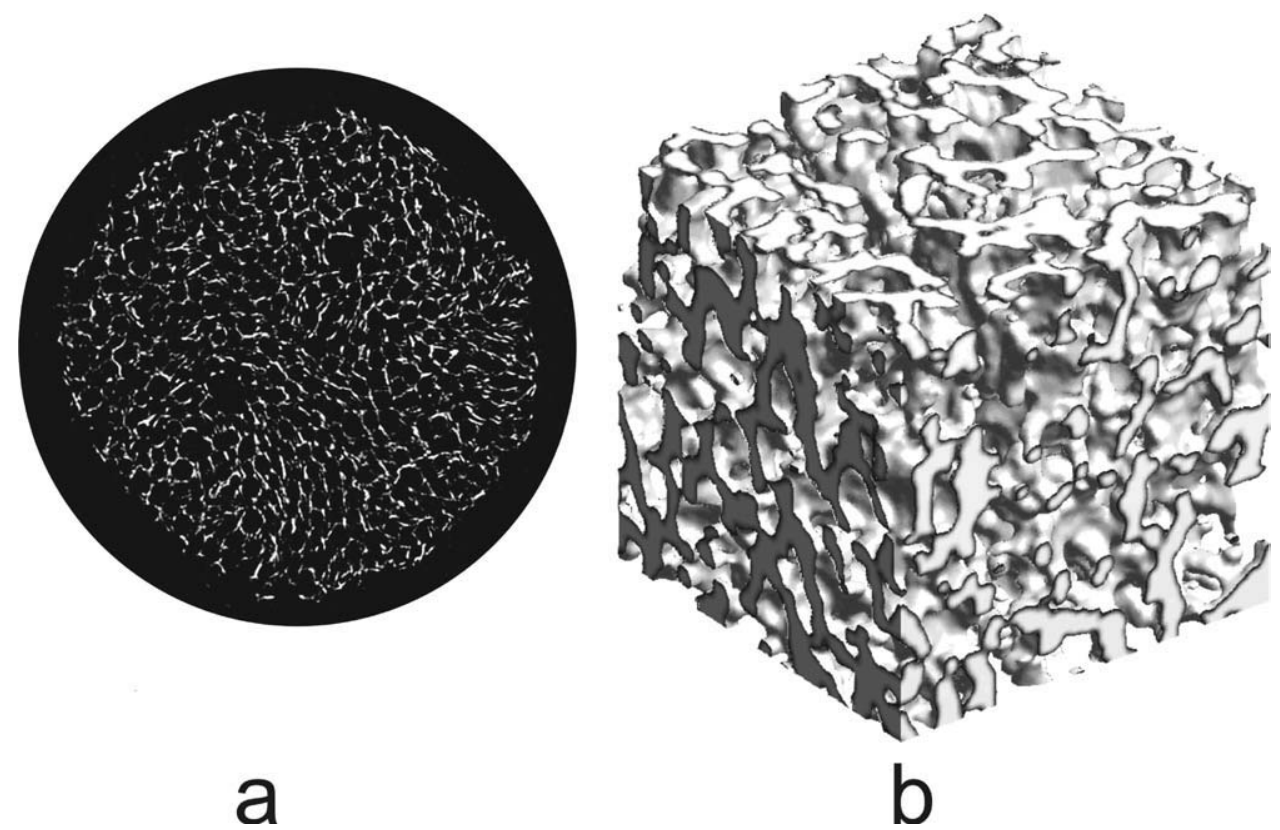

FIGURE 2. A cross-sectional $\mu \mathrm{CT}$ image (a) and 3D reconstruction (b) of a chitosan scaffold. 


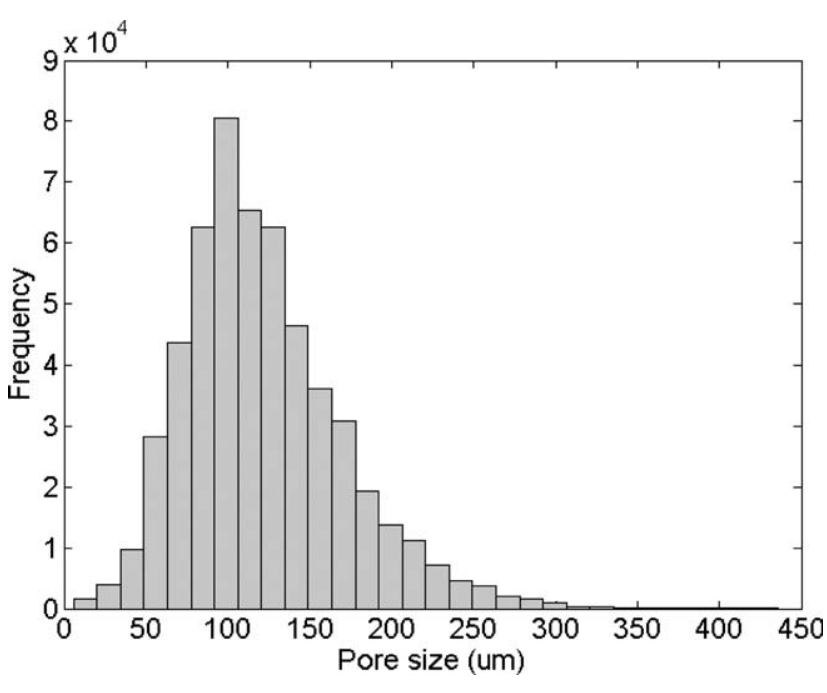

FIGURE 3. Pore size distribution obtained by image analysis of the $\mu \mathrm{CT}$ scans for $\mathrm{CHT}$ scaffold.

Triton X-100 in PBS 1X and to block unspecific binding of the antibodies, cell-scaffolds constructs were incubated with 10 vol \% foetal bovine serum in PBS blocking solution for $2 \mathrm{~h}$ at room temperature. Afterwards, samples were incubated in the diluted primary antibody solution $(10 \mu \mathrm{g} / \mathrm{mL})$ (see Table I) overnight at $4^{\circ} \mathrm{C}$, samples were washed again three times in PBS and then incubated with the respective secondary fluorochrome-conjugated antibody (Alexa 647) for $2 \mathrm{~h}$ at room temperature in dark. Finally, samples were washed three times with PBS before mounting the coverslip with a drop of vectashield (Vector Laboratories) containing DAPI to counterstain cell nuclei (blue). A Leica TCS SP2 AOBS (Leica Microsystems Heidelberg GmbH, Mannheim, Germany) confocal laser scanning microscopy (CLSM) was used. Two-dimensional pseudocolor images (255 grey levels) were gathered with a size of $1024 \times 1024$ pixels.

To visualize type I collagen, the cell-scaffold constructs were monitored in the confocal microscope, using a $20 \mathrm{X}$ Plan-Apochromat Lambda Blue 0.70 IMM objective, with a

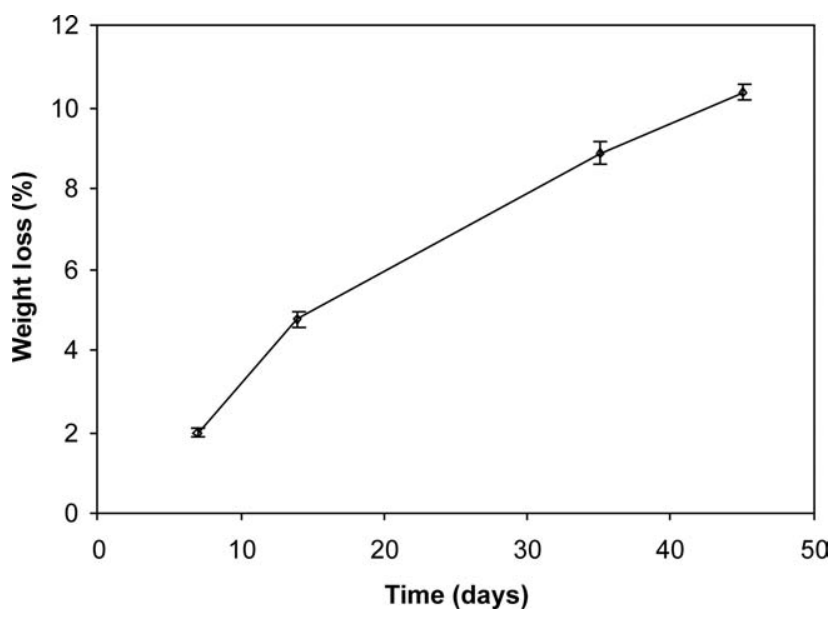

FIGURE 4. Weight loss of chitosan scaffold as a function of degradation time in PBS with $1 \mu \mathrm{g} / \mathrm{ml}$ of lysozyme. Data are shown as mean \pm standard deviation $(n=3)$.

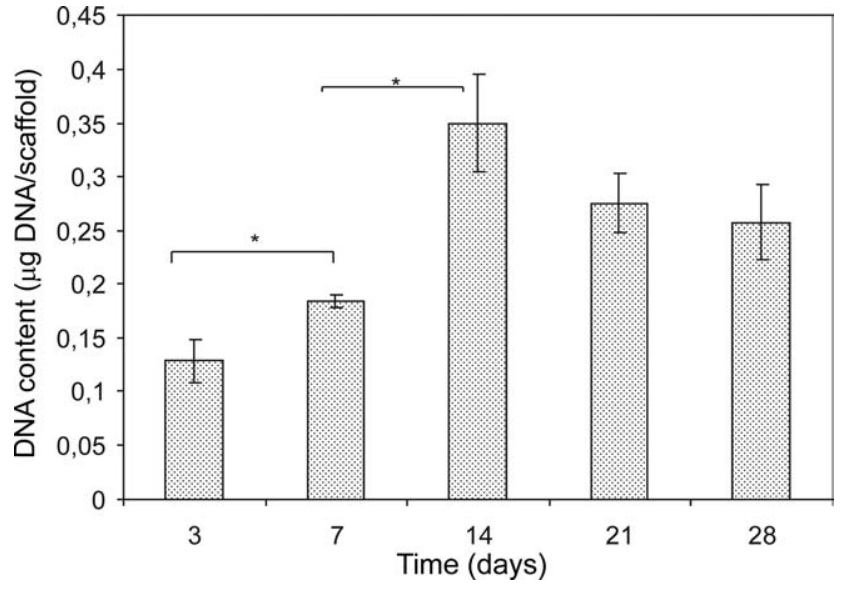

FIGURE 5. DNA content of GBMSCs cultured into $\mathrm{CHT}$ scaffolds. Data show the average and its level of statistical significance $(p<0.05)$. The * indicates significant differences.

double excitation ( 405 and $633 \mathrm{~nm}$ ) and a double emission system (411-451 nm and 650-760 nm), with two multipliers for blue and red fluorescence. Double-labeled preparation was monitored in the confocal microscope, using a 40X Plan-Apochromat 1.25 N.A. oil objective, with a double excitation ( $405 \mathrm{~nm}, 561 \mathrm{~nm}$ ) and a double emission system (411-451 nm, 571-664 nm), with two multipliers for blue and red fluorescence to determine ALP activity and OC.

\section{Statistical analysis}

Data were expressed as mean \pm standard deviation (SD). A oneway Anova test was used to conduct statistical analysis, and statistical significance was accepted at the probability level $p<0.05$.

\section{RESULTS}

\section{Morphology and characterization of CHT scaffolds}

The methodology used in this study to prepare CHT scaffolds results in the formation of 3-D scaffolds with both micro and macroporosity. Figure 1 shows the morphology of the porous material examined by SEM. The surface image

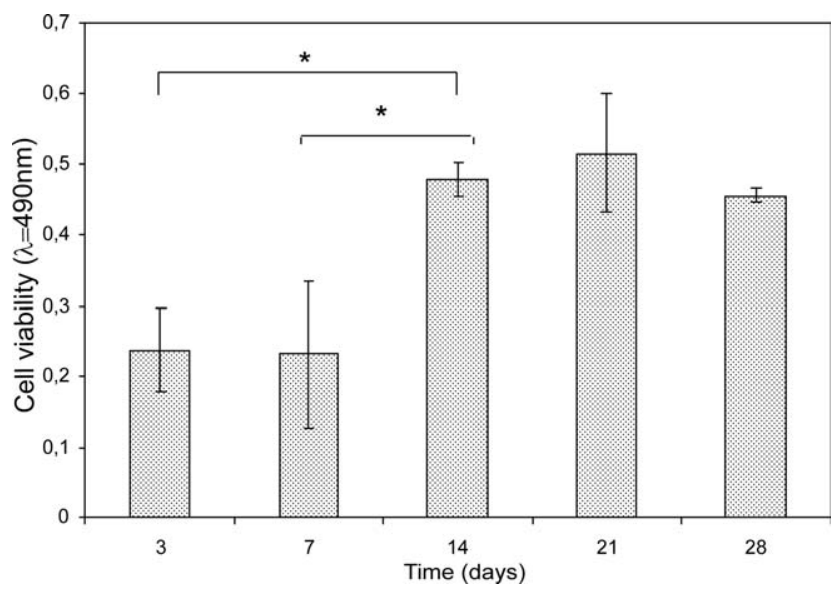

FIGURE 6. GBMSCs viability into chitosan scaffolds after 3, 7, 14, 21, and 28 days of culture. Data show the average and its level of statistical significance $(p<0.05)$. The * indicates significant differences. 


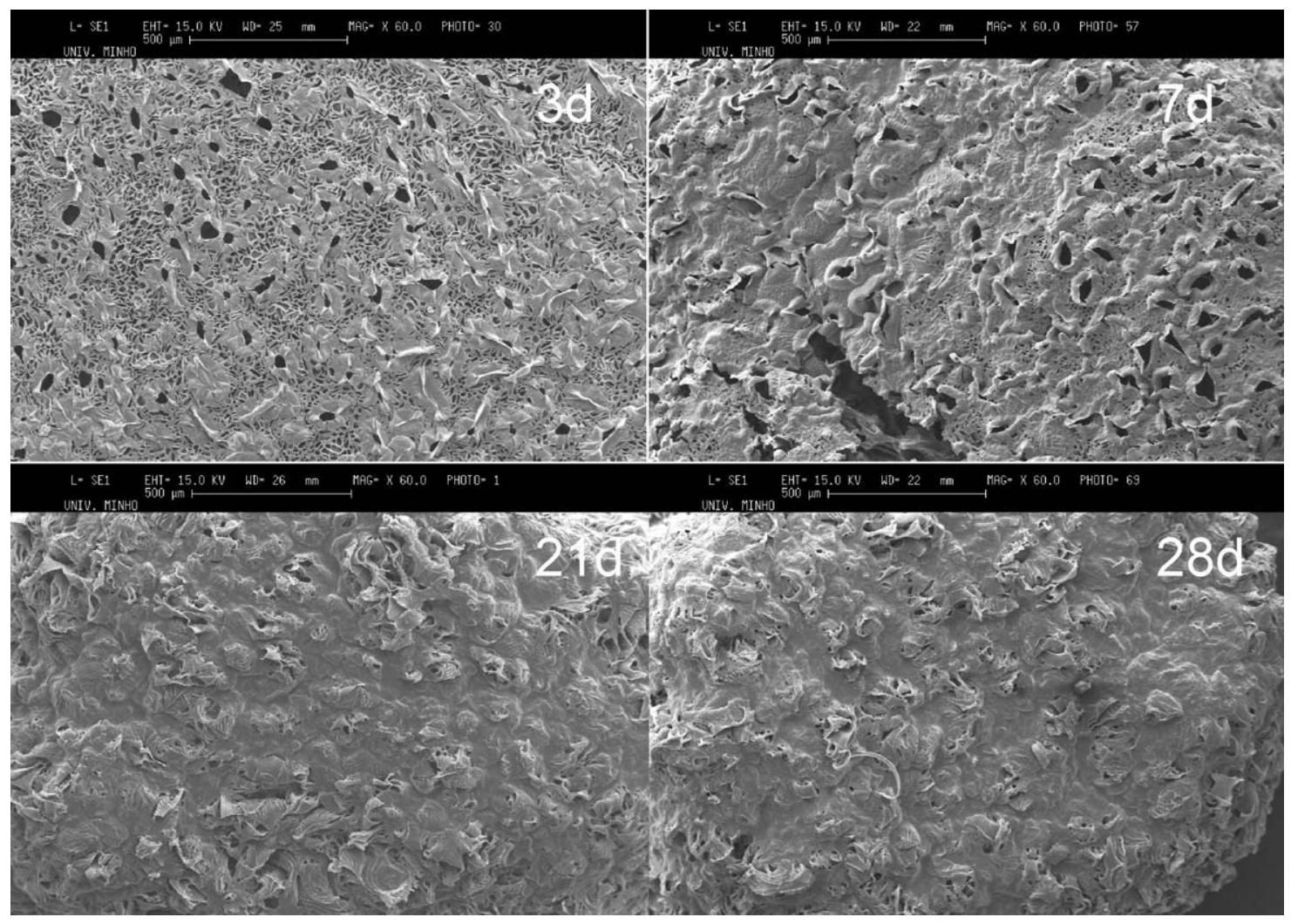

FIGURE 7. SEM microphotographs of CHT scaffolds surface cultured with GBMSCs.

of the material [Fig. 1(A) and inset] shows micro (pore size around $10 \mu \mathrm{m})$ and macropores evenly distributed. The cross-section view clearly shows the interconnectivity of the macropores [Fig. 1(B)].

More insight in the pore connectivity can be obtained using $\mu-\mathrm{CT}$ analysis that allows simultaneous evaluation of the threedimensional micropores structure and pore shape. Figure 2 shows a 2D cross-section slice of sequential scanning and a 3D reconstruction of the full CHT scaffold from the $\mu$-CT slices.

The $\mu$-CT images show, in good agreement with SEM cross-section pictures an interconnected highly porous structure. Pore shape is almost spherical as expected, due to the geometry of the porogen used. Average porosity of the materials resulted in $84 \% \pm 2 \%$.

Pore size distribution was analyzed using ESTRA, ${ }^{30}$ an in-house software, as a complementary technique. Figure 3 represents the pore size distribution of the scaffold. The mean pore size is $\sim 140 \mu \mathrm{m}$, lower than the diameter of PEMA microspheres used as porogen $(200 \mu \mathrm{m})$. The reduction of the pore size can be a consequence of the dehydration characteristics of ethanol as a solvent, however, note that the contraction of the pore size takes place isotropically. From Figure 3, it is not possible to distinguish the double pore size as in SEM microphotographs.

\section{Degradation studies}

To mimic the biodegradation rate of CHT scaffolds in physiological conditions, ${ }^{34}$ the degradation studies performed in this work were carried out on PBS ( $\mathrm{pH} 7.4,37^{\circ} \mathrm{C}$ ) in pres- ence of $10 \mu \mathrm{g} / \mathrm{mL}$ of lysozyme. The enzyme biodegrades the polysaccharide by hydrolyzing the $\beta 1,4 \quad \mathrm{~N}$-acetylglucosamine groups of CHT chains. Figure 4 shows the weight loss profile as a function of time. It was observed that the degradation rates of CHT scaffolds increase as incubation time increases; moreover a slight degradation after 45 days was achieved, only 10 wt $\%$ of weight lose.

\section{Culture of GBMSCs into CHT scaffolds}

Cell viability, proliferation, and morphology. GBMSCs suspension $(50 \mu \mathrm{L})$ were seeded into the CHT scaffolds at a cellular density of $1 \times 10^{5}$ cells/scaffold using a microsyringe and incubated for $1 \mathrm{~h}$ to stimulate the cell adhesion to the scaffold. After $1 \mathrm{~h}$, the cell/scaffold construct was transferred to a new 48-well plate; to test only the cells attached to the porous scaffolds, and $1 \mathrm{~mL}$ of fresh osteogenic medium were added to each well.

The proliferation of GBMSCs evaluated after each incubation time is shown in Figure 5. DNA content reveals a significant enhancement from day 3 to day 21, reaching a plateau at this time point. The DNA analysis was corroborated by MTS (Fig. 6) verifying that cells not only proliferate well in CHT scaffolds but also were viable.

Figure 7 shows the morphological analysis of the surface of the CHT scaffolds seeded with GBMSCs and cultured in osteogenic medium at different culture times: $3,7,21$, and 28 days. As can be seen, cells spread on the surface of the scaffold and after 28 days culture the whole surface was covered. To observe the cell morphology inside the micro 


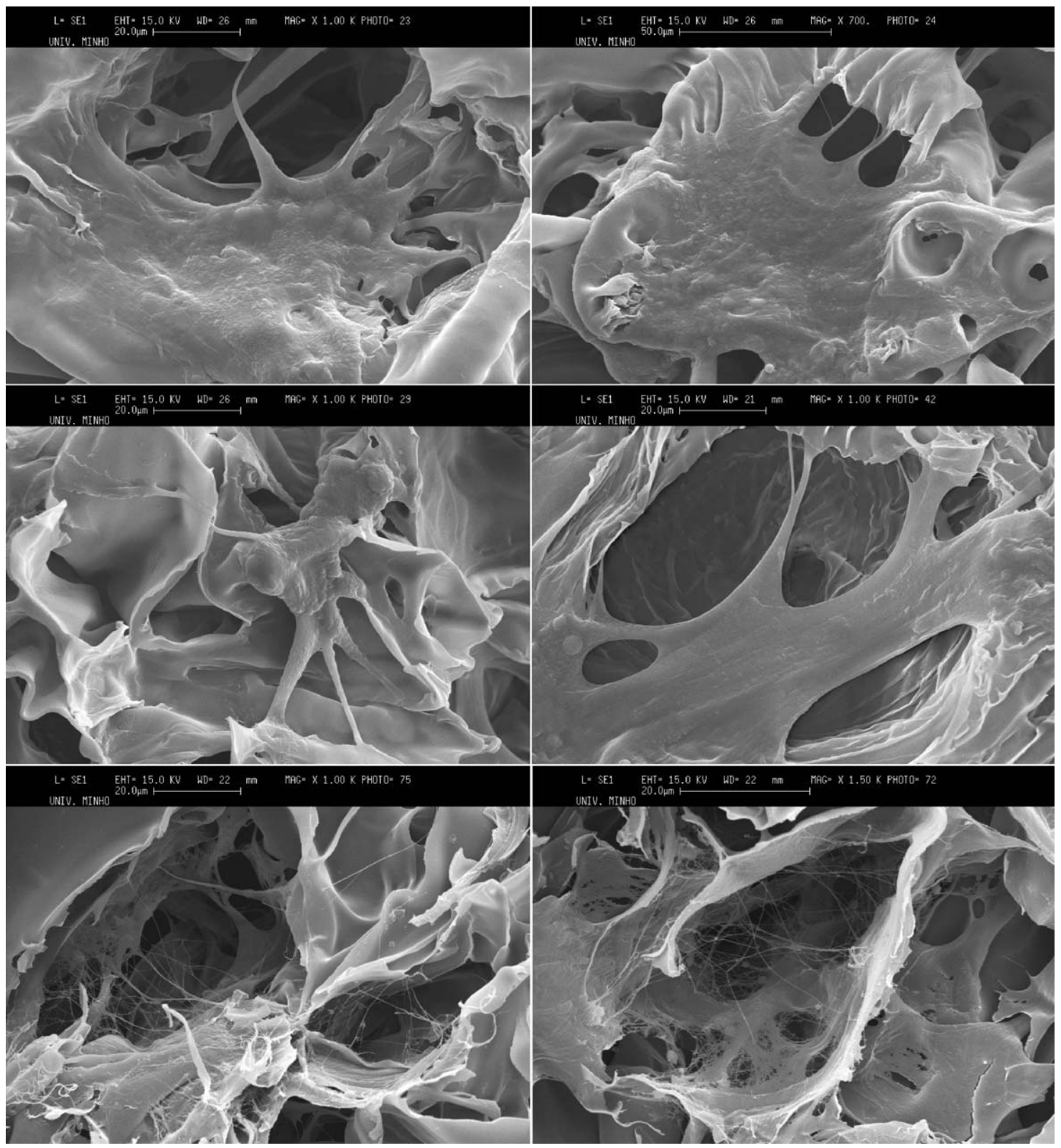

FIGURE 8. SEM microphotographs of cross-sections of scaffold-cells constructs at 14 days culture show morphology, adhesion, and extracellular matrix production of GBMSCs into CHT scaffolds.

and macropores, the constructs were cross-sectioned in thick slices and observed by SEM (Fig. 8).

The morphology of GBMSCs in the porous structure of CHT scaffolds showed spreading cells with multiple filopodia adhered to the scaffold wall, establishing bridges between adjacent pores. The presence of extracellular matrix (ECM), as a three-dimensional fibril network, could already be detected after 14 days of culture. The observed results suggest that the material system promoted intercellular contacts and the spatial arrangement of the cells.

\section{GBMSCs differentiation assessment by expression of osteogenic specific marker}

The expression of osteoblastic phenotype was assessed by type I collagen, ALP activity and OC secretion. Cell-scaffold constructs were cross-sectioned in thick slices $(\sim 1 \mathrm{~mm})$ and observed with confocal microscopy. CLSM images of GBMSCs cultured for 14 and 21 days are represented in Figure 9. Nuclei were counterstained with DAPI (blue) and the expression of osteoblastic-associated markers (type I collagen, OC and ALP) were followed by alexa-647 (red) linked to the secondary antibody.

Self-fluorescence of $\mathrm{CHT}^{36}$ allows observing the micro and macropore structure of the scaffold that is especially clear in Figures 9(a) (in blue) and 10(b) (in violet due to the superimposition of both fluorescences: blue DAPI and red alexa-647). These images confirm the isotropic contraction of the scaffold during porogen extraction and pore connectivity as previously accounted for by SEM and $\mu$-CT. Numerous cells can be observed not only at the surface of 


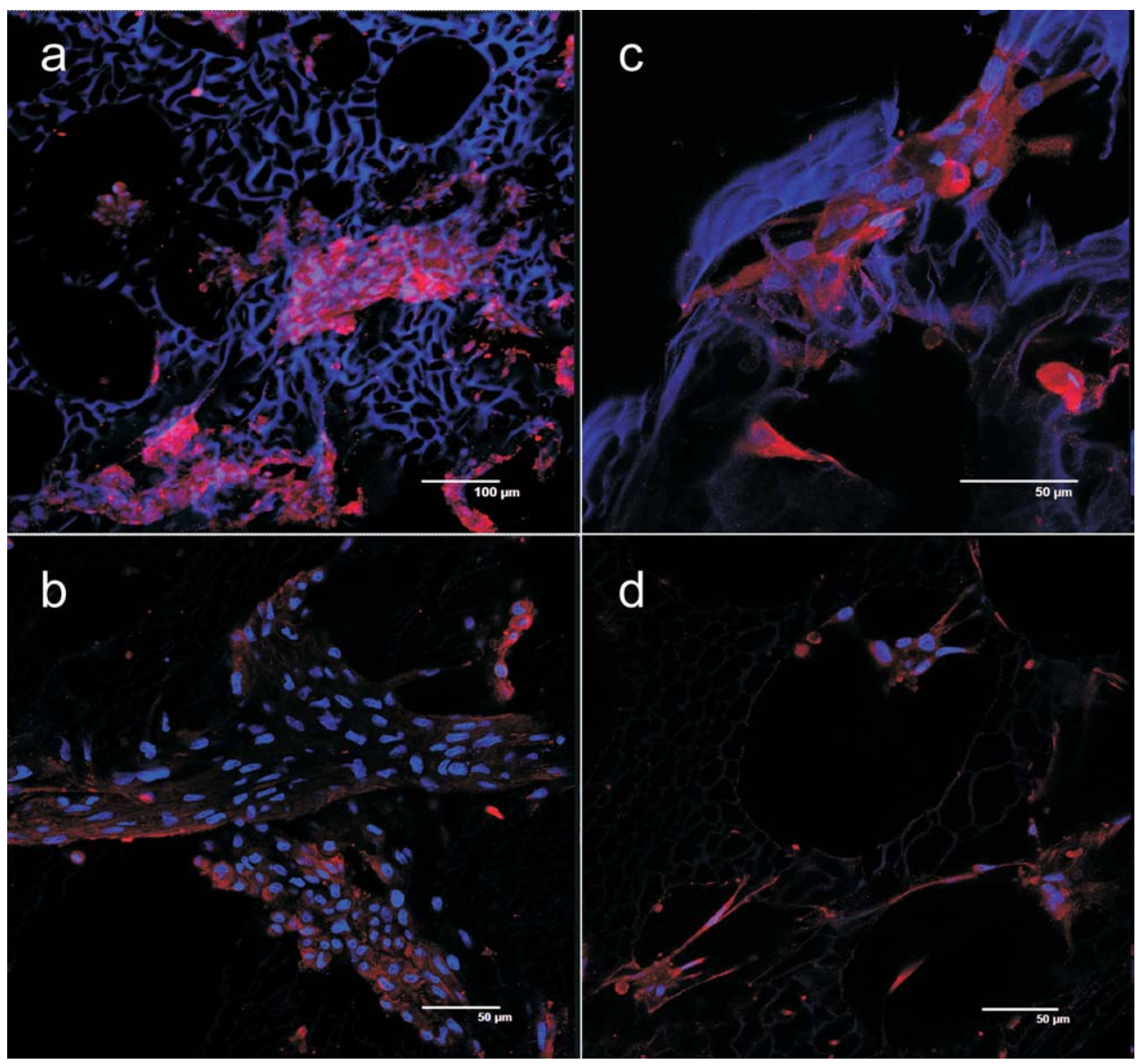

FIGURE 9. Immunofluorescence analysis of type I collagen and osteocalcin by GBMSCs cultured at 14 and 21 days (a,c) into chitosan scaffolds in osteogenic media. Osteocalcin expression was detected for 21 and 28 days $(b, d)$. [Color figure can be viewed in the online issue, which is available at wileyonlinelibrary.com.]

the samples (Fig. 7), but also throughout the complete cross-section of the scaffold. Cells are well distributed along the interior of the scaffold localized mainly in the macropores although some of them even penetrate into the micropores. It is worth noting that good cell distribution was obtained even if cell seeding was performed under static conditions, without use of a bioreactor, which is known to be an important tool in seeding cells into 3D scaffolds. ${ }^{37-41}$

The expression of type I collagen was detected at 14 and 21 days respectively [Fig. $9(\mathrm{a}, \mathrm{c})$ ] thus showing the production of collagenous matrix. ALP activity was assessed by both colorimetric analysis and immunofluorescence staining (Fig. 10).

ALP activity of GBMSCs cultured into CHT scaffold in osteogenic media increases along the first two weeks (14 days) and then decreases [Fig. 10(a)]. Immunofluorescence of the cell/scaffold construct after 2 weeks of culture revealed ALP expression [Fig. 10(b)]. Mineralized tissue in CHT scaffolds were detected by von Kossa staining after 3 weeks of culture [Fig. 10(c)].

These results show an enhancement of the osteoblastic phenotype expression levels. OC secretion by GBMSCs in osteogenic media and mineralized tissue was detected from day 21 respectively [Figs. 9(b,d) and 10(c)], which demonstrate that osteoblastic differentiation was achieved in these constructs.

\section{DISCUSSION}

The essential constituents for successful tissue engineering include functionally active cells, biocompatible scaffolds for in vitro differentiation/proliferation and subsequent implantation into the defect site, and bioactive molecules stimulating differentiation such as growth factors. ${ }^{42}$ To facilitate cell attachment and proliferation, high specific surface area and interconnected pore structure are desirable. In this study, CHT was selected as a biocompatible polymer to design a potential substrate for bone regeneration due its promising properties such as cell/tissue compatibility, biodegradability, and functionality. ${ }^{43}$ The ability of CHT to support cell attachment and proliferation is attributed to its chemical properties and hydrophilic character. $^{44,45}$ In orthopedic applications, considerable attention have been given to CHT based materials. Interesting characteristics that render CHT suitable for this purpose are an intrinsic antibacterial nature and the ability to be molded in 3D materials with highly porous structure and interconnected pores with different shapes and sizes under mild conditions, which facilitates 

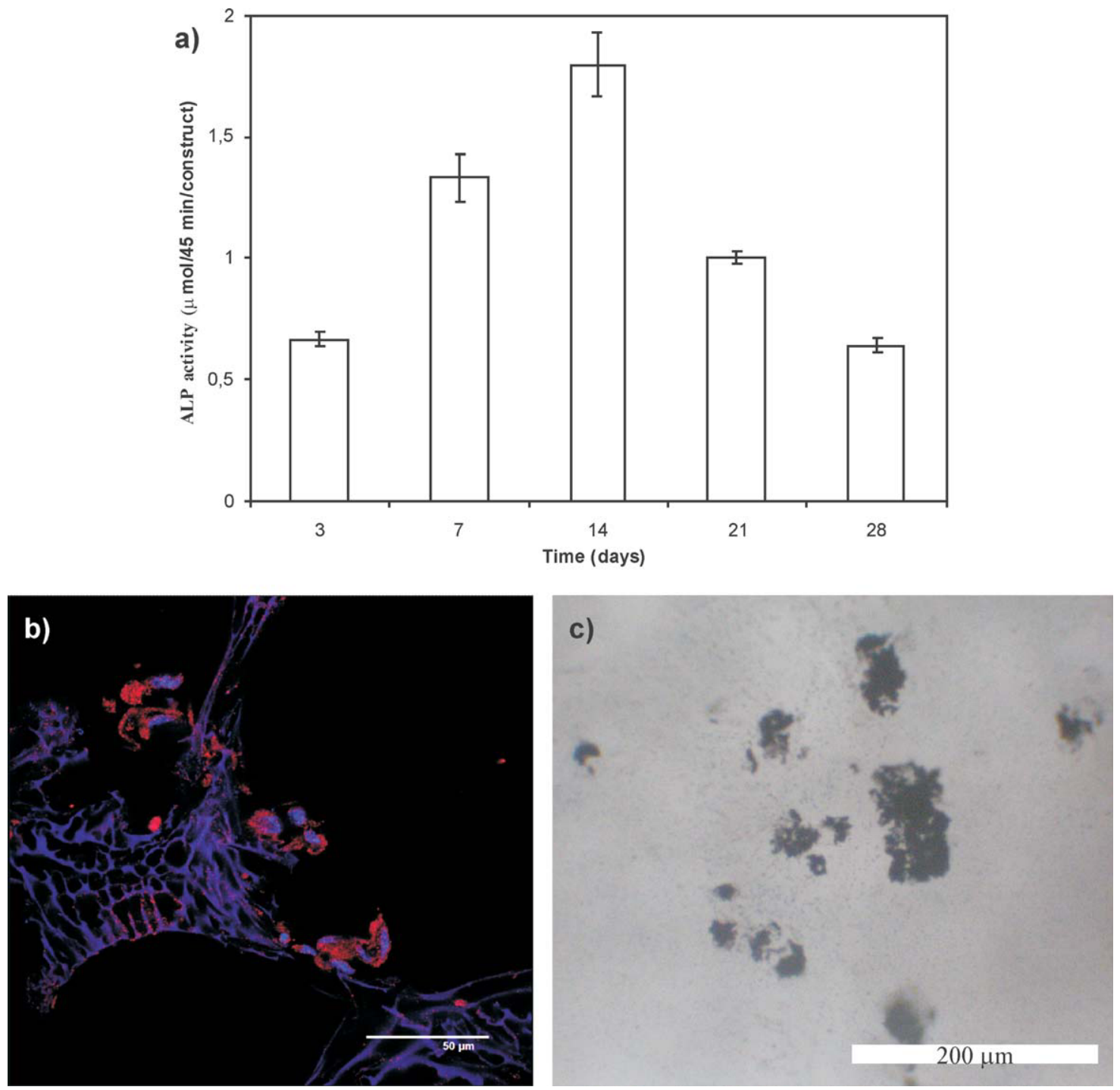

FIGURE 10. Expression of ALP activity assay of GBMSCs cultured into CHT scaffold was assessed by: (a) colorimetric analysis and (b) immunofluorescence staining. The ALP activity was detected at 14 days. Mineralization of CHT scaffolds were confirmed by von Kossa staining (c). [Color figure can be viewed in the online issue, which is available at wileyonlinelibrary.com.]

the osteoconductivity and enhance the bone formation both in vitro and in vivo. ${ }^{40,46-48}$

In the study presented here, CHT scaffolds with a hierarchical pore structure was obtained using an advanced method that combines the techniques of freeze-gelation and particulate leaching. The resulting scaffolds have an interconnected pore structure with small and large pores (Fig. 1). Small pores are due to the freeze-gelation process and result in a high surface area to allow cell attachment and proliferation and to facilitate cell penetration into the scaffold. On the other hand, large pores formed by the leached out porogen facilitate cell growth and allow enough volume to be filled in with cell-secreted extracellular matrix that can thus create and organize their own three-dimensional tissue like structures. Flow transport of nutrients and metabolic waste is also facilitated by a high pore interconnectivity. In previous works, Shin et al. ${ }^{27}$ studied the biological response of porcine bone marrow derived MSCs on poly (lactide-co-glycolide) scaffolds with interconnected pore structure on two distinct lengths to bone tissue regeneration. They obtained promising results on cell attachment, proliferation and osteogenic differentiation. More recently, some studies ${ }^{49-52}$ demonstrated the feasibility of CHT based scaffolds for bone tissue engineering.

It has been shown that injection of a cell suspension in the middle of the scaffold piece is a very effective cell seeding procedure in this kind of material. ${ }^{53}$ Because of the high pore interconnectivity; cells are forced to flow through the pore structure and adhere to the macropore walls. Although the total volume of the cell suspension is only slightly larger than the volume of the scaffold, a part of the cells leaves the scaffold and finally can adhere on its surface or even on the culture well. To ensure that cell culture initiates only with the cells adhered to the scaffold, the samples were moved to new wells after a short time. SEM microphotographs and immunofluorescence show that a layer of cells 
and extracellular matrix grows on the surface of the scaffold while the pores of the scaffold are filled by cells as well. DNA quantification and MTS assay prove cell proliferation and viability, although it is not possible to asses the differential proliferative capacity of cells situated on the scaffold surface and thus behaving as in a monolayer culture and those situated inside the pores with a three-dimensional neighborhood, it is worth noting that cells can be observed in the whole cross-section of the scaffold up to 28 days culture, this proves the good performance of the scaffold in what respect to allow nutrients diffusion even if culture is not performed in a bioreactor. The high porosity of the scaffold and the particular pore architecture with high pore interconnectivity seems to allow for cell viability at a distance up to $1.5 \mathrm{~mm}$ from the surface.

Another important characteristic of the scaffolds is their biodegradability. Ideally scaffolds used in tissue engineering are intended to degrade slowly after implantation and be replaced by the new tissue. ${ }^{54}$ CHT has been shown to be degraded mainly by lysozyme, which commonly exists in various human body fluids and tissues. ${ }^{32-34}$ Lysozyme could hydrolyze the bindings between $\mathrm{N}$-acetylmuramic acid and $\mathrm{N}$-acetylglucosamine in some bacteria's cell wall. Therefore, in this research, we utilized lysozyme as degradation enzyme. The profile of degradation of CHT scaffolds found in our study can be explained due the lack of consecutive $\mathrm{N}$-acetylglucosamine residues, the CHT used in this study has $85 \%$ deacetylation degree. The obtained results are in agreement with the previous results reported in the literature in a number of studies. ${ }^{55-57}$

The development of osteoblastic-like cells from bone marrow stromal precursors suggest the evolution of the cells trough different developmental or maturational stages that are revealed by changes in the levels of expression of the known osteoblast-associated markers. ${ }^{58}$ Generally, osteoblast-differentiation takes places in three steps, which include proliferation of cells, maturation and mineralization of extracellular matrix. During proliferation, expression of type I collagen is relatively high and then it decreases, ${ }^{59}$ whereas during maturation and synthesis of ECM, specific osteoblast-phenotype markers such as ALP and OC are expressed. Alkaline phosphatase increases but then decreases when mineralization is well advanced ${ }^{60}$ while OC appears approximately with mineralization. ${ }^{61,62}$

CHT scaffold with hierarchical pore structure allowed the osteogenic differentiation of GBMSCs and their proliferation, which are related to the synthesis, deposition, and subsequent mineralization of the collagenous extracellular matrix.

\section{CONCLUSIONS}

GBMSCs seeded in CHT scaffolds with micro and macropores are able to attach and gradually proliferate along 4 weeks of culture. SEM images showed that the substrate surface becomes completely covered by a dense layer of cells and viable cells are uniformly distributed in the pore structure and a fibrillar ECM production was detected. GBMSCs expressed ALP, secreted OC and mineralized tissue was observed, which confirmed that the differentiation along the osteoblastic lineage occurred.

\section{ACKNOWLEDGMENTS}

The authors are indebted to the work of Angel Alberich Bayarri (Hospital Quirón-Valencia, Spain) and Laura Nieto Charques (Siemens España, Spain) for their technical assistance and for developing the CAD tool to study 3D structures. The group in the CIPF acknowledges founding in the framework of the collaboration agreement among the Instituto de Salud Carlos III, the Consellería de Sanidad de la Comunidad Valenciana and the CIPF for the "Investigación Básica y Traslacional en Medicina Regenerativa."

\section{REFERENCES}

1. Hutmacher DW. Scaffold design and fabrication technologies for engineering tissues-state of the art and future perspectives. J Biomater Sci Polym Ed 2001;12:107-124.

2. Friedenstein AJ, Chailakhyan RK, Gerasimov UV. Bone marrow osteogenic stem cells: In vitro cultivation and transplantation in diffusion chambers. Cell Tissue Kinet 1987;20:263-272.

3. Maniatopoulos C, Sodek J, Melchor AH. Bone formation in vitro by stromal cells obtained from bone marrow of young adult rats. Cell Tissue Res 1988;254:317-330.

4. Kassem M. Stem cells: Potential therapy for age-related diseases. Ann N Y Acad Sci 2006;1067:436-442.

5. Takahashi Y, Yamamoto M, Tabata Y. Sponges Composed of Gelatin and $\beta$-tricalcium Phosphate. Biomaterials 2005;26:3587-3596.

6. Fischer EM, Layrolle P, Van Blitterswijk CA, De Bruijn JD. Bone formation by mesenchymal progenitor cells cultured on dense and microporous hydroxyapatite particles. Tissue Eng 2003;9: 1179-1188.

7. Li M, Mondrinos MJ, Chen X, Gandhi MR, Ko FK, Lelkes PI. Coelectrospun poly(lactide-co-glycolide), gelatin, and elastin blends for tissue engineering scaffolds. J Biomed Mater Res A 2006;79: 963-973.

8. Wei G, Ma PX. Structure and properties of nano-hydoxyapatite/ polymer composite scaffolds for bone tissue engineering. Biomaterials 2004;25:4749-4757.

9. Lin CY, Kikuchi N, Hollister SJ. A novel method for biomaterial scaffold internal architecture design to match bone elastic properties with desired porosity. J Biomech 2004;37:623-636.

10. Takahashi $Y$, Yamamoto M, Tabata Y. Osteogenic differentiation of mesenchymal stem cells in biodegradable sponges composed of gelatin and beta-tricalcium phosphate. Biomaterials 2005;26: 3587-3596.

11. Li X, Feng Q, Liu X, Dong W, Cui F. Collagen-based implants reinforced by chitin fibres in a goat shank bone defect model. Biomaterials 2006;27:1917-1923.

12. Shen FH, Zeng Q, Li Q, Choi L, Balian G, Li X, Laurencin CT. Osteogenic differentiation of adipose-derived stromal cells treated with GDF-5 cultured on a novel three-dimensional sintered microsphere matrix. Spine J 2006;6:615-623.

13. Krajewska B. Membrane-based processes performed with use of chitin/chitosan materials. Sep Purif Technol 2005;41:305-312.

14. Ho MH, Kuo PY, Hsieh HJ, Hsien TY, Hou LT, Lai JY, Wang DM. Preparation of porous scaffolds by using freeze-extraction and freeze-gelation methods. Biomaterials 2004;25:129-138.

15. Madihally SJ, Mattew HWT. Porous chitosan scaffolds for tissue engineering. Biomaterials 1999;20:1133-1142.

16. Babensee JE, Anderson JM, Mclntire LV, Mikos AG. Host response to tissue engineered devices. Adv Drug Deliv Rev 1998; 33:111-139.

17. Seeherman H, Li R, Wozney J. A review of preclinical program development for evaluating injectable carriers for osteogenic factors. J Bone Joint Surg Am 2003;85:96-108. 
18. Lee J, Cuddihy MJ, Kotov NA. Three-dimensional cell culture matrices: State of the art. Tissue Eng 2008;14:61-86.

19. Arpornmaeklong $P$, Pripatnanont $P$, Suwatwirote N. Properties of chitosan-collagen sponges and osteogenic differentiation of ratbone-marrow stromal cells. Int J Oral Maxillofac Surg 2008;37: 357-366.

20. Seol YJ, Lee JY, Park YJ, Lee YM, Ku Y, Rhyu IC, Lee SJ, Han SB Chung $\mathrm{CP}$. Chitosan sponges as tissue engineering scaffolds for bone formation. Biotechnol Lett 2004;26:1037-1041.

21. Di Martino A, Sittinger M, Risbud MV. Chitosan: A versatile biopolymer for orthopaedic tissue-engineering. Biomaterials 2005;26: 5983-5990.

22. Oliveira JM, Rodrigues MT, Silva SS, Malafaya PB, Gomes ME, Viegas CA, Dias IR, Azevedo JT, Mano JF, Reis RL. Novel hydroxyapatite/chitosan bilayered scaffold for osteochondral tissueengineering applications: Scaffold design and its performance when seeded with goat bone marrow stromal cells. Biomaterials 2006;27:6123.

23. Zhang Y, Venugopal JR, El-Turki A, Ramakrishna S, Su B, Lim CT. Electrospun biomimetic nanocomposite nanofibers of hydroxyapatite/chitosan for bone tissue engineering. Biomaterials 2008;29: 4314-4322.

24. Karageorgiou V, Kaplan D. Porosity of 3D biomaterial scaffolds and osteogenesis. Biomaterials 2005;26:5474-5491.

25. Whang $\mathrm{K}$, Thomas $\mathrm{CH}$, Healy $\mathrm{KE}$, Nuber $\mathrm{G}$. A novel method to fabricate bioabsorbable scaffolds. Polymer 1995;36:837-842.

26. Whang K, Healy KE, Elenz DR, Nam EK, Tsai DC, Thomas $\mathrm{CH}$, Nuber MD, Glorieux FH, Travers R, Sprague SM. Engineering bone regeneration with bioabsorbable scaffolds with novel microarchitecture. Tissue Eng 1999;5:35-51.

27. Shin M, Abukawa H, Troulis MJ, Vacanti JP. Development of a biodegradable scaffold with interconnected pores by heat fusion and its application to bone tissue engineering. J Biomed Mater Res A 2008;84:702-709.

28. Murphy WL, Dennis RG, Kileny JL, Mooney DJ. Salt fusion: An approach to improve pore interconnectivity within tissue engineering scaffolds. Tissue Eng 2002;8:43-52.

29. da Silva RMP, Mano JF, Reis RL. Straightforward determination of the degree of $\mathrm{N}$-acetylation of chitosan by means of first-derivative UV spectrophotometry. Macromol Chem Phys 2008;209: 1463-1472.

30. Nieto Charques L, Moratal D, Martí Bonmatí L. EsTra: A Computer Aided Diagnostic Tool to Study the Trabecular Bone and Other 3D Structures. Center for Technology Transfer, Universitat Politècnica de València/Polytechnic University of Valencia, Valencia, Spain, 2006.

31. Jianzhuang L, Wenqing L, Yupeng T. International Conference on Circuits and Systems, Vol 1. China: Conference Proceedings; 1991. p 325-327.

32. Brouwer J, van Leeuwen-Herberts T, Otting-van de Ruit M. Determination of lysozyme in serum, urine, cerebrospinal fluid and feces by enzyme unmunoassay. Clin Chim Acts 1984;142:21-30.

33. Porstmann B, Jung K, Schmechta H, Evers U, Pergande M, Porstmann T, Kramm HJ, Krause H. Measurement of lysozyme in human body fluids: Comparison of various enzyme immunoassay techniques and their diagnostic application. Clin Biochem 1989; 22:349-355.

34. Freier T, Koh HS, Kazazian K, Shoichet MS. Controlling cell adhesion and degradation of chitosan films by $\mathrm{N}$-acetylation. Biomaterials 2005;26:5872-5878.

35. Reis RL, Mendes SC, Cunha AM, Bevis MJ. Processing and in vitro degradation of starch/EVOH thermoplastic blends. Polym Int 1997;43:347-352.

36. García Cruz DM, Coutinho DF, Costa Martinez E, Mano JF, Gómez Ribelles JL, Salmerón Sánchez M. Blending polysaccharides with biodegradable polymers. II. Structure and biological response of chitosan/polycaprolactone blends. J Biomed Mater Res B 2008;87: 544-554.

37. Martin I, Wendt D, Heberer M. The role of bioreactors in tissue engineering. Trends Biotechnol 2004;22:80-86.

38. Freed LE, Vunjak-Novakovic G. Tissue engineering bioreactors. In: Vacanti JP, Vacanti JP, editors. Principles of Tissue Engineering. London: Academic Press; 2000. p143-156.
39. Qi X, Liu JG, Chang Y, Xu XX. Comparative study on seeding methods of human bone marrow stromal cells in bone tissue engineering. Chin Med J (Engl) 2004;117:576-580.

40. Janssen FW, Oostra J, Oorschot A, van Blitterswijk CA. A perfusion bioreactor system capable of producing clinically relevant volumes of tissue-engineered bone: In vivo bone formation showing proof of concept. Biomaterials 2006;27: 315-323.

41. Stiehler $M$, Bunger $C$, Baatrup $A$, Lind $M$, Kassem M, Mygind $T$. Effect of dynamic 3-D culture on proliferation, distribution, and osteogenic differentiation of human mesenchymal stem cells. J Biomed Mater Res 2009;89:96-107.

42. Langer R, Vacanti JP. Tissue Engineering. Science 1993;260: 920-926.

43. Jiang T, Kumbar SG, Nair LS, Laurencin CT. Biologically active chitosan systems for tissue engineering and regenerative medicine. Curr Top Med Chem 2008;8:354-364.

44. Zhao F, Grayson WL, Ma T, Bunnell B, Lu WW. Effects of hydroxyapatite in 3-D chitosan-gelatin polymer network on human mesenchymal stem cell construct development. Biomaterials 2006;27:1859-1867.

45. Thein-Han WW, Misra RDK. Biomimetic chitosan-nanohydroxyapatite composite scaffolds for bone tissue engineering. Acta Biomater 2009;5:1182-1197.

46. Marino AD, Sitinger M, Risbud MV. Chitosan: A versatile biopolymer for orthopaedic tissue-engineering. Biomaterials 2005;26: 5983-5990.

47. Khor E, Lim LY. Implantable applications of chitin and chitosan. Biomaterials 2003;24:2339-2349.

48. Thein-Han WW, Kitiyanant Y, Misra RDK. Chitosan as a scaffold matrix for tissue engineering. Mater Sci Technol 2008;24: 1062-1075.

49. Yilgor P, Tuzlakoglu K, Reis RL, Hasirci N, Hasirci V. Incorporation of a sequential BMP-2/BMP-7 delivery system into chitosan-based scaffolds for bone tissue engineering. Biomaterials 2009;30: 3551-3559.

50. Peter M, Binulal NS, Nair SV, Selvamurugan N, Tamura H, Jayakumar R. Novel biodegradable chitosan-gelatin/nano-bioactive glass ceramic composite scaffolds for alveolar bone tissue engineering. Chem Eng J 2010;158:353-361.

51. Jiang T, Khan Y, Nair LS, Abdel-Fattah WI, Laurencin CT. Functionalization of chitosan/poly(lactic acid-glycolic acid) sintered microsphere scaffolds via surface heparinization for bone tissue engineering. J Biomed Mater Res A 2010;93:1193-1208.

52. Alves da Silva ML, Crawford A, Mundy JM, Correlo VM, Sol P, Bhattacharya M, Hatton PV, Reis RL, Neves NM. Chitosan/polyester-based scaffolds for cartilage tissue engineering: Assessment of extracellular matrix formation. Acta Biomater 2010;6: 1149-1157.

53. Escobar Ivirico JL, Salmerón Sánchez M, Gómez Ribelles JL, Monleón Pradas M, Soria JM, Gomes ME, Reis RL, Mano JF. Proliferation and differentiation of goat bone marrow stromal cells in 3D scaffolds with tunable hydrophilicity. J Biomed Mater Res Appl Biomater 2009;91:277-286.

54. Yang F, Cui WJ, Xiong Z, Liu L, Bei JZ, Wang SG. Poly(L,L-lactideco-lycolide)/tricalcium phosphate composite scaffold and its various changes during degradation in vitro. Polym Degrad Stab 2006;91:3065-3073.

55. Cunha-Reis C, TuzlaKoglu K, Baas E, Yang Y, ElHaj A, Reis RL. Influence of porosity and fibre diameter on the degradation of chitosan fibre-mesh scaffolds and cell adhesion. J Mater Sci A 2007;18:195-200.

56. Zhang $H$, Neau $H$. In vitro degradation of chitosan by a commercial enzyme preparation: Effect of molecular weight and degree of deacetylation. Biomaterials 2001;22:1653-1658.

57. Marques $A P$, Reis $R L$, Hunt $A$. Evaluation of the potential of starch-based biodegradable polymers in the activation of human inflammatory cells. J Mater Sci 2003;14:167-173.

58. Aubin JE, Turksen K, Heersche JNM. "Osteoblastic cell lineage." In: Noda M, Editor. Cellular and Molecular Biology of Bone. New York: Academic Press; 1993. p 1-45.

59. Owen TA, Aronow MS, Barone LM, Bettencourt B, Stein GS, Lian JB. Pleiotropic effects of vitamin D on osteoblast gene expression 
are related to the proliferative and differentiated state of the bone cell phenotype: Dependency upon basal levels of gene expression, duration of exposure, and bone matrix competency in normal rat osteoblast cultures. Endocrinology 1991;128: 1496-1504.

60. Miyake T, Cameron AM, Hall BK. Stage-specific expression patterns of alkaline phosphatase during development of the first arch skeleton in inbred C57BL/6 mouse embryos. J Anat 1997;190: 239-260.
61. Markose ER, Stein JL, Stein GS, Lian JB. Vitamin D-mediated modifications in protein-DNA interactions at two promoter elements of the osteocalcin gene. Proc Natl Acad Sci USA 1990;87: 1701-1705.

62. Pockwinse SM, Wilming LG, Conlon DM, Stein GS, Lian JB. Expression of cell growth and bone specific genes at single cell resolution during development of bone tissue-like organization in primary osteoblast cultures. J Cell Biochem 1992;49: 310-323. 